\title{
Orthogonal Left Derivations of Semi-Prime Rings
}

\section{Ali Al-Hachami KH*}

Department of Mathematics, Wasit University, Al Kut, Wasit, Iraq

\begin{abstract}
In this paper we show a few outcomes concerning two remaining deductions on a semi-prime ring are displayed. These outcomes are identified with an outcome which is motivated by Posner's hypothesis. This outcome affirms that if $R$ is a 2-torsion free semi-prime ring, $\delta$ and $g$ are non-zero remaining inductions of $R$ with the end goal that $g$ is $a$ surjective on $R$, and $g(y) \delta(x)=g(x) \delta(y)$ for all $x, y \in R$. At that point $\delta g$ can't be a non-zero left derivation. A thought of orthogonal left derivations emerges here.
\end{abstract}

Keywords: Left derivation; Orthogonal left derivations; Prime ring; Semi-prime ring

\section{Introduction}

All through $\mathrm{R}$ will speak to a cooperative ring. $\mathrm{R}$ is said to be 2 - torsion free if $2 x=0, x \in R$ implies $x=0$ [1]. Review that $R$ is prime if $x R y=0$ implies $x=0$ or $y=0$, and $R$ is semi-prime if $x R x=0$ suggests $x=0$. Ref. [2], characterized the accompanying thought. An added substance mapping $\delta: R \rightarrow R$ is known as a left inference if $\delta(x y)=x \delta(y)+y \delta(x)$ holds for all $\mathrm{x}, \mathrm{y} \in \mathrm{R}$. Different properties of left deductions can be found in refs. [3-8].

Two additive mapping $\delta, g: R \rightarrow R$ is said to be orthogonal if:

$(\mathrm{x}) \operatorname{Rg}(\mathrm{y})=0=\mathrm{g}(\mathrm{y}) \operatorname{R} \delta(\mathrm{x})$ for all $\mathrm{x}, \mathrm{y} \in \mathrm{R}$.

Brešar and Vukman [9] presented the idea of orthogonality for two inductions $\delta$ and g on a semi-prime ring, and they introduced a few important and adequate conditions for $\delta$ and $g$ to be orthogonal. In ref. [10] the creators presented orthogonal summed up inferences on a semi-prime ring and they introduced a few outcomes concerning two summed up determinations on a semi-prime ring. Their outcomes are a speculation of after effects of Brešar and Vukman in ref. [9]. What's more [11], in the creators presented orthogonal $(\sigma, \tau)$-determinations and orthogonal summed up $(, \tau)$-deductions. Their outcomes dreamy a few aftereffects of Brešar and Vukman [9]. In this paper, our point is to give similar consequences of Brešar and Vukman to orthogonal left derivations [9].

For a generalized semi-prime ring $\mathrm{R}$ and a perfect $\mathrm{U}$ of $\mathrm{R}$, it is outstanding that the left and right annihilators of $\mathrm{U}$ in $\mathrm{R}$ agree [12]. We indicate the annihilator of $U$ by Ann (U). Take note of that UnAnn $(\mathrm{U})=0$ and $\mathrm{U} \oplus \operatorname{Ann}(\mathrm{U})$ is a fundamental perfect of $\mathrm{R}[12]$.

\section{Materials and Methods}

In the accompanying, we give the documentation of orthogonal left derivations.

\section{Definition 2.1}

Left derivations $\delta$ and g are called orthogonal if,

$(x) \operatorname{Rg}(y)=0=g(y) R \delta(x)$, for all $x, y \in R$. itself.

Clearly a non-zero remaining deduction cannot be orthogonal on

Give us a chance to consider a straightforward case of the non-zero orthogonal left derivations.

Example: Give $S$ a chance to be a prime ring and set $R=S \oplus S$. At that point $\mathrm{R}$ is a semi-prime ring. Give $\delta$ and $\mathrm{g}$ a chance to be two nonzero remaining deductions of $\mathrm{S}$. At that point the maps $\delta_{1}$ and $\mathrm{g}_{1}$ from $\mathrm{R}$ to $\mathrm{R}$, which are characterized by:

$\delta_{1}((\mathrm{x}, \mathrm{y}))=(\delta(\mathrm{x}), 0)$ and $\mathrm{g}_{1}((\mathrm{x}, \mathrm{y}))=(0, \mathrm{~g}(\mathrm{y}))$, for all $\mathrm{x}, \mathrm{y} \in \mathrm{S}$, are non-zero left derivations of $\mathrm{R}$.

Then $\delta_{1}$ and $g_{1}$ are orthogonal.

Presently, to get the primary outcomes, we require the accompanying lemmas:

\section{Lemma 2.2 (Lemma 1 [9])}

Give $\mathrm{R}$ a chance to be a 2-torsion free semi-prime ring and $\mathrm{a}, \mathrm{b}$ the components of $\mathrm{R}$. At that point the accompanying conditions are proportional:

(i) $\mathrm{axb}=0$, for all $\mathrm{x} \in \mathrm{R}$.

(ii) $\mathrm{bxa}=0$, for all $\mathrm{x} \in \mathrm{R}$.

(iii) $\mathrm{axb}+\mathrm{bxa}=0$, for all $\mathrm{x} \in \mathrm{R}$.

On the off chance that one of these conditions is satisfied then abdominal muscle $\mathrm{ab}=\mathrm{ba}=0$

\section{Lemma 2.3 (Lemma $2.2[9])$}

Give $\mathrm{R}$ a chance to be a semi-prime ring. What's more, assume that added substance mappings $f$ and $h$ of $R$ into itself fulfill satisfy $f(x)$ $\operatorname{Rh}(\mathrm{x})=0$, for all $\mathrm{x} \in \mathrm{R}$. Then $\mathrm{f}(\mathrm{x}) \mathrm{Rh}(\mathrm{y})=0$, for all $\mathrm{x}, \mathrm{y} \in \mathrm{R}$.

\section{Results and Discussion}

In Theorem 3.1, we will demonstrate that If $\delta$ and $g$ are orthogonal left derivations of a 2-torsion free semi-prime ring $\mathrm{R}$, then there exists a fundamental perfect $\mathrm{E}$ of $\mathrm{R}$, with the end goal that the confinements of $\delta$ and $g$ to $E$ are fitting direct wholes.

*Corresponding author: Ali Al-Hachami $\mathrm{KH}$, Department of Mathematics, Wasit university, Al Kut, Wasit, Iraq, Tel: 009647832315025; E-mail: alhachamia@uowasit.edu.iq

Received January 21, 2017; Accepted June 27, 2017; Published July 02, 2017

Citation: Ali Al-Hachami KH (2017) Orthogonal Left Derivations of Semi-Prime Rings. J Generalized Lie Theory Appl 11: 270. doi: 10.4172/1736-4337.1000270

Copyright: (c) 2017 Ali Al-Hachami KH. This is an open-access article distributed under the terms of the Creative Commons Attribution License, which permits unrestricted use, distribution, and reproduction in any medium, provided the original author and source are credited. 


\section{Theorem 3.1}

Give $\mathrm{R}$ a chance to be a 2-torsion free semi-prime ring. Give $\delta$ and $\mathrm{g}$ a chance to be left derivations of $\mathrm{R}$. At that point the accompanying conditions are equal:

(i) $\delta$ and g are orthogonal.

(ii) There exist standards $\mathrm{E}_{1}$ and $\mathrm{E}_{2}$ of $\mathrm{R}$ with the end goal that:

$\mathrm{E}_{1} \cap \mathrm{E}_{2}=0$ and $\mathrm{E}=\mathrm{E}_{1} \oplus \mathrm{E}_{2}$ is a basic perfect of $\mathrm{R}$.

(a) maps $\mathrm{R}$ into $\mathrm{E}_{1}$ and $\mathrm{g}$ maps $\mathrm{R}$ into $\mathrm{E}_{2}$.

(b) The restriction of $\delta$ to $\mathrm{E}=\mathrm{E}_{1} \oplus \mathrm{E}_{2}$ is a direct sum $\delta_{1} 0_{2}$, where $\delta_{1}: \mathrm{E}_{1} \rightarrow \mathrm{E}_{1}$ is a left derivation of $\mathrm{E}_{1}$ and $0_{2}: \mathrm{E}_{2} \rightarrow \mathrm{E}_{2}$ is zero. If $\delta_{1}=0$ then $\delta=0$.

(c) The restriction of $\mathrm{g}$ to $\mathrm{E}=\mathrm{E}_{1} \oplus \mathrm{E}_{2}$ is a direct sum $0_{1} \oplus \mathrm{g}_{2}$, where $0_{1}: E_{1} \rightarrow E_{1}$ is zero and $g_{2}: E_{2} \rightarrow E_{2}$ is a left derivation of $E_{2}$. If $g_{2}=0$ then $g=0$.

In Theorem 3.2, we give a few vital and adequate conditions for the orthogonality of two left derivations.

\section{Theorem 3.2}

Give $\mathrm{R}$ a chance to be a 2-torsion free semi-prime ring. Let $\delta$ and $\mathrm{g}$ be left derivations of $\mathrm{R}$ such that $\mathrm{g}$ is a surjective on $\mathrm{R}$, and $\mathrm{g}(\mathrm{y})$ $\delta(\mathrm{x})=\mathrm{g}(\mathrm{x}) \delta(\mathrm{y})$, for all $\mathrm{x}, \mathrm{y} \in \mathrm{R}$. Then $\delta$ and $\mathrm{g}$ are orthogonal if and only if one of the following conditions holds:

(i) $\mathrm{g}(\mathrm{x}) \delta(\mathrm{x})=0$, for all $\mathrm{x} \in \mathrm{R}$.

(ii) $\delta(x) g(x)=0$, for all $x \in R$.

(iii) $\mathrm{g}(\mathrm{x}) \delta(\mathrm{x})+\delta(\mathrm{x}) \mathrm{g}(\mathrm{x})=0$, for all $\mathrm{x} \in \mathrm{R}$.

(iv) $\delta g=0$.

(v) $g \delta=0$.

(vi) $\delta g+g \delta=0$.

(vii) $\delta \mathrm{g}$ is a left derivation.

(viii) $g \delta$ is a left derivation.

(ix) There exist a, b in R such that $(\delta g)(x)=x a+x b$, for all $x \in R$.

For the evidence of the Theorem 3.1 and Theorem 3.2, we require the accompanying lemma:

\section{Lemma 3.3}

Give $\mathrm{R}$ a chance to be a 2-torsion free semi-prime ring. Give $\delta$ and $\mathrm{g}$ a chance to be left derivations of $\mathrm{R}$. In the event that $\delta$ and $\mathrm{g}$ are orthogonal then the accompanying relations hold.

(i) $\mathrm{g}(\mathrm{x}) \delta(\mathrm{x})=0$, for all $\mathrm{x} \in \mathrm{R}$.

(ii) $\delta(\mathrm{x}) \mathrm{g}(\mathrm{x})=0$, for all $\mathrm{x} \in \mathrm{R}$.

(iii) $\mathrm{g}(\mathrm{x}) \delta(\mathrm{x})+\delta(\mathrm{x}) \mathrm{g}(\mathrm{x})=0$, for all $\mathrm{x} \in \mathrm{R}$.

(iv) $\delta g=0$.

(v) $g \delta=0$.

(vi) $\delta g+g \delta=0$.

Proof: (i) By the hypothesis we have $\delta(x) \operatorname{Rg}(\mathrm{x})=0$, for all $\mathrm{x} \in \mathrm{R}$. By Lemma 2.2, we get $\mathrm{g}(\mathrm{x}) \delta(\mathrm{x})=0$, for all $\mathrm{x} \in \mathrm{R}$.

(ii) By the hypothesis we have $\delta(\mathrm{x}) \mathrm{R} g(\mathrm{x})=0$, for all $\mathrm{x} \in \mathrm{R}$.

By Lemma 2.2, we get $\delta(\mathrm{x}) \mathrm{g}(\mathrm{x})=0$, for all $\mathrm{x} \in \mathrm{R}$. (iii) By the hypothesis we have $\delta(\mathrm{x}) \operatorname{Rg}(\mathrm{x})=0$, for all $\mathrm{x} \in \mathrm{R}$.

By Lemma 2.2, we ge $\delta(\mathrm{x}) \mathrm{g}(\mathrm{x})=\mathrm{g}(\mathrm{x}) \delta(\mathrm{x})=0$, for all $\mathrm{x} \in \mathrm{R}$.

Thus $\mathrm{g}(\mathrm{x}) \delta(\mathrm{x})+\delta(\mathrm{x}) \mathrm{g}(\mathrm{x})=0$, for all $\mathrm{x} \in \mathrm{R}$.

(iv) We have $\delta(\mathrm{x}) \mathrm{yg}(\mathrm{z})=0$, for all $\mathrm{x}, \mathrm{y}, \mathrm{z} \in \mathrm{R}$. Hence,

$$
\begin{aligned}
& 0=\delta(\delta(\mathrm{x}) \mathrm{yg}(\mathrm{z})) \\
& =\delta(\mathrm{x}) \delta(\mathrm{yg}(\mathrm{z}))+\mathrm{yg}(\mathrm{z}) \delta^{2}(\mathrm{x}) \\
& =\delta(\mathrm{x}) \mathrm{y}(\delta \mathrm{g})(\mathrm{z})+\delta(\mathrm{x}) \mathrm{g}(\mathrm{z}) \delta(\mathrm{y})+\mathrm{yg}(\mathrm{z}) \delta^{2}(\mathrm{x})
\end{aligned}
$$

The second two summands are zero since $\delta$ and g are orthogonal. Therefore, this relation reduces to $\delta(x) y(\delta g)(z)=0$, where $x, y, z$ are arbitrary elements in R. But then also $(\delta g)(z) R(\delta g)(z)=0$, for all $z \in R$. Since $\mathrm{R}$ is semi-prime, we get $(\delta \mathrm{g})(\mathrm{z})=0$.

The second two summands are zero since $\delta$ and $g$ are orthogonal. In this manner, this connection decreases to $\delta(x) y(\delta)(z)=0$, where $\mathrm{x}, \mathrm{y}$ and $\mathrm{z}$ are discretionary components in $\mathrm{R}$. Be that as it may, then likewise $(\delta \mathrm{g})(\mathrm{z}) \mathrm{R}(\delta \mathrm{g})(\mathrm{z})=0$, for all $\mathrm{z} \in \mathrm{R}$. Since $\mathrm{R}$ is semi-prime, we get $(\delta \mathrm{g})(\mathrm{z})=0$.

(v) By a similar way in (iv) we get the result.

(vi) From (iv) and (v), Lemma 2.4, we have $\delta g+g \delta=0$.

We need the following lemma to proof Theorem 3.2.

\section{Lemma 3.4}

Let $\mathrm{R}$ be a 2-torsion free semi-prime ring. Let $\delta$ and $\mathrm{g}$ be left derivations of $\mathrm{R}$ such that $\mathrm{g}$ is a surjective on $\mathrm{R}$, and $\mathrm{g}(\mathrm{y}) \delta(\mathrm{x})=\mathrm{g}(\mathrm{x}) \delta(\mathrm{y})$, for all $\mathrm{x}, \mathrm{y} \in \mathrm{R}$. Then $\delta$ and $\mathrm{g}$ are orthogonal if and only if $\mathrm{g}(\mathrm{y}) \delta(\mathrm{x})+\mathrm{g}(\mathrm{x})$ $\delta(y)=0$, for all $\mathrm{x}, \mathrm{y} \in \mathrm{R}$.

Proof: Suppose that $\mathrm{g}(\mathrm{y}) \delta(\mathrm{x})+\mathrm{g}(\mathrm{x}) \delta(\mathrm{y})=0$, for all $\mathrm{x}, \mathrm{y} \in \mathrm{R}$. By the assumption, we have $\mathrm{g}(\mathrm{y}) \delta(\mathrm{x})=0$, for all $\mathrm{x}, \mathrm{y} \in \mathrm{R}$. Since $\mathrm{R}$ is 2 -torsion free, we have $\mathrm{g}(\mathrm{y}) \delta(\mathrm{x})=0$, for all $\mathrm{x}, \mathrm{y} \in \mathrm{R}$. Take $\mathrm{x}=\mathrm{g}(\mathrm{z}) \mathrm{x}$ in the above relation, where $\mathrm{z}$ in $\mathrm{R}$, we get,

$0=\mathrm{g}(\mathrm{y}) \delta(\mathrm{g}(\mathrm{z}) \mathrm{x})$

$=\mathrm{g}(\mathrm{y}) \mathrm{g}(\mathrm{z}) \delta(\mathrm{x})+\mathrm{g}(\mathrm{y}) \mathrm{x} \delta(\mathrm{g}(\mathrm{z}))$

$=\mathrm{g}(\mathrm{y}) \mathrm{x} \delta(\mathrm{g}(\mathrm{z}))$, for all $\mathrm{x}, \mathrm{y}, \mathrm{z} \in \mathrm{R}$.

Since $\mathrm{g}$ is surjective, we get $\mathrm{g}(\mathrm{y}) \mathrm{x} \delta(\mathrm{z})=0$, for all $\mathrm{x}, \mathrm{y}, \mathrm{z} \in \mathrm{R}$.

Then $\mathrm{g}(\mathrm{y}) \mathrm{R} \delta(\mathrm{z})=0$, for all $\mathrm{y}, \mathrm{z} \in \mathrm{R}$. Using Lemma 2.2 , we see that $\delta$ and $g$ are orthogonal.

Conversely, if $\delta$ and $g$ are orthogonal, we have,

$\delta(\mathrm{x}) \operatorname{Rg}(\mathrm{y})=0$, for all $\mathrm{x}, \mathrm{y} \in \mathrm{R}$.

By Lemma 2.2, we get $\mathrm{g}(\mathrm{y}) \delta(\mathrm{x})=\mathrm{g}(\mathrm{x}) \delta(\mathrm{y})=0$, for all $\mathrm{x}, \mathrm{y} \in \mathrm{R}$.

Thus $\mathrm{g}(\mathrm{y}) \delta(\mathrm{x})+\mathrm{g}(\mathrm{x}) \delta(\mathrm{y})=0$, for all $\mathrm{x}, \mathrm{y} \in \mathrm{R}$.

Let $\delta$ and $\mathrm{g}$ be left derivations of any ring R. By a direct computation, we verify the following identities:

$$
\begin{aligned}
& (\delta \mathrm{g})(\mathrm{xy})=\mathrm{x}(\delta \mathrm{g})(\mathrm{y})+\mathrm{g}(\mathrm{y}) \delta(\mathrm{x})+\mathrm{g}(\mathrm{x}) \delta(\mathrm{y})+\mathrm{y}(\delta \mathrm{g})(\mathrm{x}) \\
& (\mathrm{g} \delta)(\mathrm{xy})=\mathrm{x}(\mathrm{g} \delta)(\mathrm{y})+\delta(\mathrm{y}) \mathrm{g}(\mathrm{x})+\delta(\mathrm{x}) \mathrm{g}(\mathrm{y})+\mathrm{y}(\mathrm{g} \delta)(\mathrm{x})
\end{aligned}
$$

We now have enough information's to prove Theorem 3.1.

Proof of Theorem 3.1: (i) $\Rightarrow$ (ii). Let $\mathrm{E}_{1}$ be an ideal of $\mathrm{R}$ generated by all $\delta(x), x \in R$, and let $E_{2}$ be Ann $\left(E_{1}\right)$, the annihilator of $E_{1}$. From eqn. (1) we see that $g(x), x \in E_{2}$, for all $x \in R$. Whenever $E_{1}$ is an ideal in a semiprime ring we have $\mathrm{E}_{1} \cap \mathrm{E}_{2}=0$ and $\mathrm{E}=\mathrm{E}_{1} \oplus \mathrm{E}_{2}$ is an essential ideal. Thus (a) and (b) are proved. 
Our next goal is to show that $\delta$ is zero on $\mathrm{E}_{2}$. Take $\mathrm{e}_{2} \in \mathrm{E}_{2}$. Then $\mathrm{e}_{1} \mathrm{e}_{2}=0$, for all $\mathrm{e}_{1} \in \mathrm{E}_{1}$. Hence $0=\delta\left(\mathrm{e}_{1} \mathrm{e}_{2}\right)=\mathrm{e}_{1} \delta\left(\mathrm{e}_{2}\right)+\mathrm{e}_{2} \delta\left(\mathrm{e}_{1}\right)$.

It is obvious from the definition of $\mathrm{E}$ that $\delta$ leaves $\mathrm{E}_{1}$ invariant, hence $e_{2} \delta\left(e_{1}\right)=0$. Then the relation above reduces to $e_{1} \delta\left(e_{2}\right)=0$. Since in a semi-prime ring the left and right and two-sided annihilators of an ideal coincide, then we have $\delta\left(e_{2}\right) \in A n n\left(E_{1}\right)=E_{2}$. But on the other hand $\delta\left(e_{2}\right)$ belongs to the set of generating elements of $E_{1}$. Thus $\delta\left(e_{2}\right) \in E_{1}$ $\mathrm{nE}_{2}=0$, which means that $\delta$ is zero on $\mathrm{E}_{2}$.

As we have mentioned above $\delta$ leaves $\mathrm{E}_{1}$ invariant. Therefore we may define a mapping $\delta_{1}: \mathrm{E}_{1} \rightarrow \mathrm{E}_{1}$ as a restriction of $\delta$ to $\mathrm{E}_{1}$. Suppose that $\delta_{1} 0$. Then $\delta$ is zero on $\mathrm{E}=\mathrm{E}_{1} \oplus \mathrm{E}_{2}$. Take e $\in \mathrm{E}$ and $\mathrm{x} \in \mathrm{R}$. We have $\delta$ $(\mathrm{ex})=\mathrm{e} \delta(\mathrm{x})+\mathrm{x} \delta(\mathrm{e})$. But $\delta(\mathrm{ex})=\delta(\mathrm{e})=0$ since ex,e $\in \mathrm{R}$.

Consequently e $\delta(\mathrm{x})=0$, for all $\mathrm{x} \in \mathrm{R}$. Thus $\delta(\mathrm{x}) \in \mathrm{Ann}(\mathrm{E})$. But ideal $\mathrm{E}$ is essential and therefore $\operatorname{Ann}(\mathrm{E})=0$. Hence $\delta(\mathrm{x})=0$, for all $\mathrm{x} \in \mathrm{R}$. Then (c) is thereby proved.

It remains to prove $(\mathrm{d})$. First we show that $\mathrm{g}$ is zero on $\mathrm{E}_{1}$. Take $\mathrm{x}$, $y, z \in R$ and set $e_{1}=x \delta(y) z$. Then $g\left(e_{1}\right)=g(x \delta(y) z)=x g(\delta(y) z)+\delta(y) z g(x)$

$=\mathrm{x} \delta(\mathrm{y}) \mathrm{g}(\mathrm{z})+\mathrm{xz}(\mathrm{g} \delta)(\mathrm{y})+\delta(\mathrm{y}) \mathrm{zg}(\mathrm{x})$.

Since $\delta$ and g are orthogonal we have $\delta(y) g(z)=0, \delta(y) z g(x)=0$ and $\mathrm{g} \delta=0$ by Lemma 3.3. Hence $\mathrm{g}\left(\mathrm{e}_{1}\right)=0$. In a similar fashion we see that $\mathrm{g}$ $(\mathrm{x} \delta(\mathrm{y}))=0, \mathrm{~g}(\delta(\mathrm{y}) \mathrm{z})=0$ and $\mathrm{g}(\delta(\mathrm{y}))=0$ by Lemma 3.3. Then $\mathrm{g}$ is zero on $\mathrm{E}_{1}$. Recall that $\mathrm{g}$ maps $\mathrm{R}$ into $\mathrm{E}_{2}$. In particular, it leaves $\mathrm{E}_{2}$ invariant. Thus, we may define $\mathrm{g}_{2}: \mathrm{E}_{2} \rightarrow \mathrm{E}_{2}$ as a restriction of $\mathrm{g}$ to $\mathrm{E}_{2}$. The proof that $\mathrm{g}_{2}=0$ implies $\mathrm{g}=0$ is the same as the proof that $\delta_{1}=0$ implies $\delta=0$.

(ii) $\Rightarrow$ (i). Clear.

Proof of Theorem 3.2: " $\delta$ and g are orthogonal" $\Rightarrow$ (i), (ii), (iii), (iv), (v) and (vi) are proved by Lemma 3 .

(i) $\Rightarrow " \delta$ and $\mathrm{g}$ are orthogonal". A linearization of $\mathrm{g}(\mathrm{x}) \delta(\mathrm{x})=0$ gives, $\mathrm{g}(\mathrm{x}) \delta(\mathrm{y})+\mathrm{g}(\mathrm{y}) \delta(\mathrm{x})=0$, for all $\mathrm{x}, \mathrm{y} \in \mathrm{R}$.

Hence $\delta$ and g are orthogonal by Lemma 4 .

(ii) $\Rightarrow " \delta$ and $\mathrm{g}$ are orthogonal". A linearization of $\delta(\mathrm{x}) \mathrm{g}(\mathrm{x})=0$ gives,

$(x) g(y)+\delta(y) g(x)=0$, for all $x, y \in R$.

Left multiplication by $\mathrm{g}(\mathrm{y})$ in the above relation gives,

$\mathrm{g}(\mathrm{y}) \delta(\mathrm{x}) \mathrm{g}(\mathrm{y})+\mathrm{g}(\mathrm{y}) \delta(\mathrm{y}) \mathrm{g}(\mathrm{x})=0$, for all $\mathrm{x}, \mathrm{y} \in \mathrm{R}$.

By the assumption, we get,

$\mathrm{g}(\mathrm{x}) \delta(\mathrm{y}) \mathrm{g}(\mathrm{y})+\mathrm{g}(\mathrm{y}) \delta(\mathrm{y}) \mathrm{g}(\mathrm{x})=0$, for all $\mathrm{x}, \mathrm{y} \in \mathrm{R}$.

Hence,

$\mathrm{g}(\mathrm{y}) \delta(\mathrm{y}) \mathrm{g}(\mathrm{x})=0$, for all $\mathrm{x}, \mathrm{y} \in \mathrm{R}$.

Since $\mathrm{g}$ is surjective, we get,

$\mathrm{g}(\mathrm{y}) \delta(\mathrm{y}) \mathrm{x}=0$,

where $\mathrm{x}, \mathrm{y}$ are arbitrary elements in $\mathrm{R}$.

Since $\mathrm{R}$ is semi-prime, we get,

$\mathrm{g}(\mathrm{y}) \delta(\mathrm{y})=0$, for all $\mathrm{y} \in \mathrm{R}$.

Therefore, by (i), Theorem 3.2, we get the result.

(iii) $\Rightarrow " \delta$ and $g$ are orthogonal". Suppose that $\mathrm{g}(\mathrm{x}) \delta(\mathrm{x})+\delta(\mathrm{x}) \mathrm{g}(\mathrm{x})=0$, for all $\mathrm{x} \in \mathrm{R}$. Then,

$\mathrm{g}(\mathrm{x}) \delta(\mathrm{x})=-\delta(\mathrm{x}) \mathrm{g}(\mathrm{x})$, for all $\mathrm{x} \in \mathrm{R}\left({ }_{*}\right)$,

A linearization of $\mathrm{g}(\mathrm{x}) \delta(\mathrm{x})+\delta(\mathrm{x}) \mathrm{g}(\mathrm{x})=0$ gives,

$\mathrm{g}(\mathrm{x}) \delta(\mathrm{y})+\mathrm{g}(\mathrm{y}) \delta(\mathrm{x})+\delta(\mathrm{x}) \mathrm{g}(\mathrm{y})+\delta(\mathrm{y}) \mathrm{g}(\mathrm{x})=0$, for all $\mathrm{x}, \mathrm{y} \in \mathrm{R}$.

By the assumption, we have $2 \mathrm{~g}(\mathrm{y}) \delta(\mathrm{x})+\delta(\mathrm{x}) \mathrm{g}(\mathrm{y})+\delta(\mathrm{y}) \mathrm{g}(\mathrm{x})=0$, for all $\mathrm{x}, \mathrm{y} \in \mathrm{R}$. Left multiplication by $\mathrm{g}(\mathrm{y})$ in the above relation, we get $2 \mathrm{~g}(\mathrm{y})$ $\mathrm{g}(\mathrm{y}) \delta(\mathrm{x})+\mathrm{g}(\mathrm{y}) \delta(\mathrm{x}) \mathrm{g}(\mathrm{y})+\mathrm{g}(\mathrm{y}) \delta(\mathrm{y}) \mathrm{g}(\mathrm{x})=0$, for all $\mathrm{x}, \mathrm{y} \in \mathrm{R}$. By $\left(_{*}\right)$ and the assumption, we obtain $2 \mathrm{~g}(\mathrm{y}) \mathrm{g}(\mathrm{x}) \delta(\mathrm{y})+\mathrm{g}(\mathrm{x}) \delta(\mathrm{y}) \mathrm{g}(\mathrm{y})-\delta(\mathrm{y}) \mathrm{g}(\mathrm{y}) \mathrm{g}(\mathrm{x})=0$, for all $x, y \in R$.

Hence $2 \mathrm{~g}(\mathrm{y}) \mathrm{g}(\mathrm{x}) \delta(\mathrm{y})+[\mathrm{g}(\mathrm{x}), \delta(\mathrm{y}) \mathrm{g}(\mathrm{y})]=0$, Take $\mathrm{g}(\mathrm{x})=\delta(\mathrm{y}) \mathrm{g}(\mathrm{y})$ in the above relation, we get $2 g(y) g(x) \delta(y)=0$, for all $x, y \in R$. Since $R$ is 2 -torsion free and $g$ is surjective, we have $g(y) x \delta(y)=0$, for all $x, y \in R$. Then $g(y) R \delta(y)=0$, for all $y \in R$.

By Lemma 2.3, we then have $g(y) R \delta(z)=0$, for all $y, z \in R$.

Using Lemma 2.2, we see that $\delta$ and $g$ are orthogonal.

(iv) $\Rightarrow " \delta$ and g are orthogonal". Suppose that $\delta g=0$. According to eqn. (2), we have,

$\mathrm{g}(\mathrm{y}) \delta(\mathrm{x})+\mathrm{g}(\mathrm{x}) \delta(\mathrm{y})=0$, for all $\mathrm{x}, \mathrm{y} \in \mathrm{R}$.

Hence, we get $\delta$ and g are orthogonal by Lemma 3.4.

(v) $\Rightarrow " \delta$ and g are orthogonal". Suppose that $g \delta=0$. According to eqn. (3), we have,

$\delta(\mathrm{y}) \mathrm{g}(\mathrm{x})+\delta(\mathrm{x}) \mathrm{g}(\mathrm{y})=0$, for all $\mathrm{x}, \mathrm{y} \in \mathrm{R}$.

Take $\mathrm{y}=\mathrm{x}$ in the above relation, we get,

$2 \delta(x) g(x)=0$, for all $x \in R$.

Since R is 2-torsion free, we have,

$\delta(\mathrm{x}) \mathrm{g}(\mathrm{x})=0$, for all $\mathrm{x} \in \mathrm{R}$.

Therefore, by (ii), Theorem 3.2, we get the result.

(vi) $\Rightarrow " \delta$ and g are orthogonal". If $\delta$ and g are any left derivations then we have by eqns. (2) and (3) that,

$(\delta \mathrm{g}+\mathrm{g} \delta)(\mathrm{xy})=\mathrm{x}(\delta \mathrm{g}+\mathrm{g} \delta)(\mathrm{y})+\mathrm{g}(\mathrm{y}) \delta(\mathrm{x})+\mathrm{g}(\mathrm{x}) \delta(\mathrm{y})+\delta(\mathrm{y}) \mathrm{g}(\mathrm{x})+\delta(\mathrm{x})$ $\mathrm{g}(\mathrm{y})+\mathrm{y}(\delta \mathrm{g}+\mathrm{g} \delta)(\mathrm{x})$

Thus, if $\delta g+g \delta=0$, then the above relation reduces to,

$\mathrm{g}(\mathrm{y}) \delta(\mathrm{x})+\mathrm{g}(\mathrm{x}) \delta(\mathrm{y})+\delta(\mathrm{y}) \mathrm{g}(\mathrm{x})+\delta(\mathrm{x}) \mathrm{g}(\mathrm{y})=0$, for all $\mathrm{x}, \mathrm{y} \in \mathrm{R}$.

Take $\mathrm{x}=\mathrm{y}$ in the above relation, then we have $2(\mathrm{~g}(\mathrm{x}) \delta(\mathrm{x})+\delta(\mathrm{x})$ $\mathrm{g}(\mathrm{x}))=0$, for all $\mathrm{x} \in \mathrm{R}$. Since $\mathrm{R}$ is 2-torsion free, we have $\mathrm{g}(\mathrm{x}) \delta(\mathrm{x})+\delta(\mathrm{x})$ $\mathrm{g}(\mathrm{x})=0$, for all $\mathrm{x} \in \mathrm{R}$. Therefore, by (iii), Theorem 3.2, we get the result.

(iv) $\Rightarrow$ (vii). Clear. have,

(vii) $\Rightarrow " \delta$ and g are orthogonal". Since $\delta \mathrm{g}$ is a left derivation. We

$(\delta \mathrm{g})(\mathrm{xy})=\mathrm{x}(\delta \mathrm{g})(\mathrm{y})+\mathrm{y}(\delta \mathrm{g})(\mathrm{x})$, for all $\mathrm{x}, \mathrm{y} \in \mathrm{R}$. Comparing this express with eqn. (2), we obtain $\mathrm{g}(\mathrm{y}) \delta(\mathrm{x})+\mathrm{g}(\mathrm{x}) \delta(\mathrm{y})=0$, for all $\mathrm{x}, \mathrm{y} \in \mathrm{R}$.

Now apply Lemma 3.4 .

(v) $\Rightarrow$ (viii). Clear.

(viii) $\Rightarrow " \delta$ and g are orthogonal". Since g $\delta$ is a left derivation. We have,

$(\mathrm{g} \delta)(\mathrm{xy})=\mathrm{x}(\mathrm{g} \delta)(\mathrm{y})+\mathrm{y}(\mathrm{g} \delta)(\mathrm{x})$, for all $\mathrm{x}, \mathrm{y} \in \mathrm{R}$. Comparing this express with eqn. (3), we obtain $\delta(y) g(x)+\delta(x) g(y)=0$, for all $x, y \in R$. 
Let $\mathrm{y}=\mathrm{x}$ in the above relation, we get $2 \delta(\mathrm{x}) \mathrm{g}(\mathrm{x})=0$, for all $\mathrm{x} \in \mathrm{R}$.

Since $\mathrm{R}$ is a 2 -torsion free, we have $\delta(\mathrm{x}) \mathrm{g}(\mathrm{x})=0$, for all $\mathrm{x} \in \mathrm{R}$.

Therefore, by (ii), Theorem 3.2, we get the result.

(iv) $\Rightarrow$ (ix). Clear.

$(\mathrm{ix}) \Rightarrow " \delta$ and g are orthogonal". For every $\mathrm{x}, \mathrm{y} \in \mathrm{R}$ we have $(\delta \mathrm{g})(\mathrm{x}$ $y)=x y a+x y b$.

That is, $\mathrm{x}(\delta \mathrm{g})(\mathrm{y})+\mathrm{g}(\mathrm{y}) \delta(\mathrm{x})+\mathrm{g}(\mathrm{x}) \delta(\mathrm{y})+\mathrm{y}(\delta \mathrm{g})(\mathrm{x})=\mathrm{xya}+\mathrm{xyb}$.

Using $(\delta g)(x)=x a+x b$ and $(\delta g)(y)=y a+y b$,

we get $2 \mathrm{~g}(\mathrm{x}) \delta(\mathrm{y})+\mathrm{yx}(\mathrm{a}+\mathrm{b})=0$. Replacing $\mathrm{x}$ by $\mathrm{y}, \mathrm{x}$ in the above relation yields that $\mathrm{y}\{2 \mathrm{~g}(\mathrm{x}) \delta(\mathrm{y})+\mathrm{yx}(\mathrm{a}+\mathrm{b})\}+2 \mathrm{xg}(\mathrm{y}) \delta(\mathrm{y})=0$

Then we have $2 \operatorname{xg}(y) \delta(y)=0$, for all $x, y \in R$.

Since $\mathrm{R}$ is 2 -torsion free, we have $\mathrm{x} g(\mathrm{y}) \delta(\mathrm{y})=0$, where $\mathrm{x}, \mathrm{y}$ are arbitrary elements in R. Since R is semi-prime, we get $g(y) \delta(y)=0$, for all $y \in R$.

Therefore, by (i), Theorem 3.2, we get the result.

A notable consequence of Posner [1] states that, if $\mathrm{R}$ is a prime ring of trademark not 2, $\delta$ and $\mathrm{g}$ are non-zero inductions of $\mathrm{R}$, then $\delta \mathrm{g}$ cannot be a derivation. The outcome which is enlivened by a hypothesis of E. Posner, states that, if $\mathrm{R}$ is a 2 -torsion free semi-prime ring, $\delta$ and $\mathrm{g}$ are non-zero left derivations of $\mathrm{R}$ such an extent that $\mathrm{g}$ is a surjective on $\mathrm{R}$, and $\mathrm{g}(\mathrm{y}) \delta(\mathrm{x})=\mathrm{g}(\mathrm{x}) \delta(\mathrm{y})$, for all $\mathrm{x}, \mathrm{y} \in \mathrm{R}$. At that point $\delta \mathrm{g}$ cannot be a non-zero left derivation. One can consider (vii) and (iv), Theorem 3.2 as a proof of this outcome.

We now express a few outcomes of Theorem 3.2.

\section{Corollary 3.3}

Give $\mathrm{R}$ a chance to be a prime ring of trademark not equivalent 2. Give $\delta$ and $\mathrm{g}$ be left derivations of $\mathrm{R}$ with the end goal that $\mathrm{g}$ is a surjective on $\mathrm{R}$, and $\mathrm{g}(\mathrm{y}) \delta(\mathrm{x})=\mathrm{g}(\mathrm{x}) \delta(\mathrm{y})$, for all $\mathrm{x}, \mathrm{y} \in \mathrm{R}$. On the off chance that $\delta$ and $g$ are fulfill one of the states of Theorem 3.2, then either $\delta=0$ or $\mathrm{g}=0$.

Since a non-zero left derivation cannot be orthogonal on itself we see that (i), Theorem 3.2 yield the accompanying outcome.

\section{Corollary 3.4}

Let $\mathrm{R}$ be a 2 -torsion free semi-prime ring. And let $\delta$ be a left derivation of $\mathrm{R}$ such that $\delta$ is a surjective on $\mathrm{R}$, and $\delta(\mathrm{y}) \delta(\mathrm{x})=\delta(\mathrm{x}) \delta(\mathrm{y})$, for all $\mathrm{x}, \mathrm{y} \in \mathrm{R}$. If $\delta(\mathrm{x})^{2}=0$, for all $\mathrm{x} \in \mathrm{R}$, then $\delta=0$.

According to (vii), Theorem 3.2, we have,

\section{Corollary 3.5}

Let $\mathrm{R}$ be a 2 -torsion free semi-prime ring. And let $\delta$ be a left derivation of $\mathrm{R}$ such that $\delta$ is a surjective on $\mathrm{R}$, and $\delta(\mathrm{y}) \delta(\mathrm{x})=\delta(\mathrm{x}) \delta(\mathrm{y})$, for all $\mathrm{x}, \mathrm{y} \in \mathrm{R}$. If $\delta^{2}$ is also a left derivation, then $\delta=0$.

Similarly, using (ix), Theorem 3.2, we obtain,

\section{Corollary 3.6}

Let $\mathrm{R}$ be a 2-torsion free semi-prime ring. And let $\delta$ be a left derivation of $\mathrm{R}$ such that $\delta$ is a surjective on $\mathrm{R}$, and $\delta(\mathrm{y}) \delta(\mathrm{x})=\delta(\mathrm{x}) \delta(\mathrm{y})$, for all $\mathrm{x}, \mathrm{y} \in \mathrm{R}$. If there exist $\mathrm{a}, \mathrm{b} \in \mathrm{R}$ such that $\delta^{2}(\mathrm{x})=\mathrm{xa}+\mathrm{x} b$, for all $\mathrm{x} \in \mathrm{R}$, then $\delta=0$.

It is normal to inquire as to whether there is any association between left derivations $\delta$ and $\mathrm{g}$ of a ring $\mathrm{R}$, If $\delta^{2}=\mathrm{g}^{2}$ or if $\delta(\mathrm{x})^{2}=\mathrm{g}(\mathrm{x})^{2}$, for each $\mathrm{x} \in \mathrm{R}$. In the accompanying hypotheses, we give certifiable answer of this question.

\section{Theorem 3.7}

Let $\mathrm{R}$ be a 2 -torsion free semi-prime ring. Let $\delta$ and $\mathrm{g}$ be left derivations of $\mathrm{R}$ such that $\mathrm{g}$ is a surjective on $\mathrm{R}$, and $\mathrm{g}(\mathrm{y}) \delta(\mathrm{x})=\mathrm{g}(\mathrm{x}) \delta(\mathrm{y})$, for all $\mathrm{x}, \mathrm{y} \in \mathrm{R}$. If $\delta^{2}=\mathrm{g}^{2}$, then $\delta+\mathrm{g}$ and $\delta$-g are orthogonal.

Proof: From $\delta^{2}=\mathrm{g}^{2}$ it follows immediately that, $(\delta+\mathrm{g})(\delta-\mathrm{g})+(\delta-\mathrm{g})$ $(\delta+\mathrm{g})=0$. Hence $\delta+\mathrm{g}$ and $\delta$-g are orthogonal by $(\mathrm{vi})$, Theorem 3.2 .

\section{Corollary 3.8}

Let $\mathrm{R}$ be a prime ring of characteristic not equal 2 . Let $\delta$ and g be left derivations of $\mathrm{R}$ such that $\mathrm{g}$ is a surjective on $\mathrm{R}$, and $\mathrm{g}(\mathrm{y}) \delta(\mathrm{x})=\mathrm{g}(\mathrm{x}) \delta(\mathrm{y})$, for all $\mathrm{x}, \mathrm{y} \in \mathrm{R}$. If $\delta^{2}=\mathrm{g}^{2}$ then either $\delta=\mathrm{g}$ or $\delta=\mathrm{g}$.

\section{Theorem 3.9}

Let $\mathrm{R}$ be a 2-torsion free semi-prime ring. Let $\delta$ and $\mathrm{g}$ be left derivations of $\mathrm{R}$ such that $\mathrm{g}$ is a surjective on $\mathrm{R}$, and $\mathrm{g}(\mathrm{y}) \delta(\mathrm{x})=\mathrm{g}(\mathrm{x})$ $\delta(y)$, for all $\mathrm{x}, \mathrm{y} \in \mathrm{R}$. If $\delta(\mathrm{x})^{2}=\mathrm{g}(\mathrm{x})^{2}$, for all $\mathrm{x} \in \mathrm{R}$, then $\delta+\mathrm{g}$ and $\delta$-g are orthogonal.

Proof: Note that $(\delta+\mathrm{g})(\mathrm{x})(\delta-\mathrm{g})(\mathrm{x})+(\delta-\mathrm{g})(\mathrm{x})(\delta+\mathrm{g})(\mathrm{x})=0$, for all $\mathrm{x} \in \mathrm{R}$. Now apply (iii), Theorem 3.2.

\section{Corollary 3.10}

Let $\mathrm{R}$ be a prime ring of characteristic not equal 2. Let $\delta$ and $\mathrm{g}$ be left derivations of $\mathrm{R}$ such that $\mathrm{g}$ is a surjective on $\mathrm{R}$, and $\mathrm{g}(\mathrm{y}) \delta(\mathrm{x})=\mathrm{g}(\mathrm{x})$ $\delta(y)$, for all $\mathrm{x}, \mathrm{y} \in \mathrm{R}$. If $\delta(\mathrm{x})^{2}=\mathrm{g}(\mathrm{x})^{2}$, for all $\mathrm{x} \in \mathrm{R}$, then either $\delta=-\mathrm{g}$ or $\delta=\mathrm{g}$.

\section{References}

1. Posner E (1957) Derivations in Prime Rings. Proc Amer Math Soc 8: 10931100.

2. Brešar M, Vukman J (1990) On Left Derivations and Related Mappings. Proc Amer Math Soc 110(1): 7-16.

3. Ashraf M (2005) On Left $(\theta, \phi)$-Derivations in Prime Rings. Arch Math (Brno) 41: 157-166.

4. Ashraf M, Rehman N (2000) On Lie Ideal and Jordan Left Derivations of Prime Rings. Arch Math (Brno) 36(3): 201-206.

5. Ashraf M, Rehman N, Shaker A (2001) On Jordan Left Derivations of Lie Ideals in Prime Rings. Southeast Asian Bull Math 25(3): 379-382.

6. Deng Q (1992) On Jordan Left Derivations. Math J Okayama Univ 34: 145-147.

7. Vukman J (1997) Jordan Left Derivations on Semiprime Rings. Math J Okayama Uni 39: 1-6.

8. Zaidi SMA, Ashraf M, Al S (2004) On Jordan Ideals and Left $(\theta, \theta)$ Derivations in Prime Rings. IJMMS 37: 1957-1964.

9. Brešar M, Vukman J (1991) Orthogonal Derivations and An Extension of A Theorem of Posner. Radovi Matematički 5: 237-246.

10. Argaç N, Nakajima A, Albaş E (2004) On Orthogonal Generalized Derivations of Semiprime Rings. Turk J Math 28: 185-194.

11. Lbaşi G, Aydin N (2007) Orthogonal Generalized ( $\sigma, \mathrm{T})$-Derivations of Semiprime Rings. Sibirsk Mat Zh 48(6): 1222-1227.

12. Kharchenko VK (1991) Automorphisms and Derivations of Associative Rings Kluwer Academic Publishers. 